\title{
Family empowerment and family ability to self-care for heart failure patients in the intermediate care room
}

\author{
Alfrina Hany ${ }^{1}$, Eni Yulistianingsih ${ }^{2}$, Bintari Ratih Kusumaningrum ${ }^{3}$ \\ ${ }^{1}$ Department of Medical Surgical Nursing, Faculty of Medicine, Universitas Brawijaya, Malang, Indonesia \\ ${ }^{2}$ Saiful Anwar General Hospital, Malang, Indonesia \\ ${ }^{3}$ Department of Emergency Nursing, Faculty of Medicine, Universitas Brawijaya, Malang, Indonesia
}

\begin{tabular}{l} 
Article Info \\
\hline Article history: \\
Received April 20, 2021 \\
Revised Nov 4, 2021 \\
Accepted Nov 16, 2021 \\
\hline
\end{tabular}

\section{Keywords:}

Family empowerment

Heart failure

Patient self-care

\begin{abstract}
Heart failure is a chronic disease that has a high rehospitalization rate. The cause of rehospitalization is due to inadequate self-care behavior. For that we need the role of the family in self-care by means of family empowerment. The purpose of this study was to determine the relationship between family empowerment and the ability of families to do self-care in the intermediate care room in Malang. This study a cross sectional design and consecutive sampling technique with 100 subjects. The family empowerment scale (FES) and contribution caregiver self care heart failure index (CCSCHFI) are used to assess families' abilities to care for themselves. The statistical test used is the Pearson correlation test. The mean value of family empowerment is 127.00 and the ability to do self-care is 48.28. Pearson correlation test results obtained p-value $0.000<$ alpha 0.05 . In heart failure patients, there is a high correlation between family support and their ability to self-care. Family empowerment and ability to do self-care is lacking due to a lack of family knowledge about heart failure and its treatment. It is recommended that the nurse be more maintenance in providing education related to patient self-care to the family during treatment by empowering the family.
\end{abstract}

This is an open access article under the CC BY-SA license.

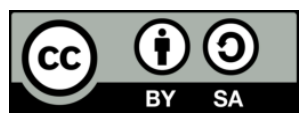

\section{Corresponding Author:}

Alfrina Hany

Department of Medical Surgical Nursing, Faculty of Medcine, Universitas Brawijaya, Indonesia

Puncak Dieng Street, Malang, East Java 65151, Indonesia

Email: hanie.fk@ub.ac.id

\section{INTRODUCTION}

Heart failure is a life-threatening condition that has been designated as a global health priority. In the United States, there were 5.8 million patients living with heart failure in 2012 and it is expected to increase to 8.5 million by 2030 [1]. In outpatients with chronic heart failure conditions, rehospitalization is one of the strongest prognostic factors in increasing the mortality rate [2]. The high rate of rehospitalization places a considerable burden on the health care system [3]. We discovered 49 occurrences of re-hospitalization in heart failure patients in May-July 2019 based on the findings of a preliminary research performed at the Malang hospital. The high rate of rehospitalization can be caused by psychosocial, social and economic factors that limit adherence to medication, self-monitoring and follow-up [4]. One way to reduce the incidence of rehospitalization of heart failure patients is by increasing self-care [5].

Self-care is important in the management of chronic diseases such as heart failure. Self-care is defined as the promotion of maintaining health through independent practice and management of diseases such as taking medication or weighing regularly [6]. Self-care in patients with heart failure includes taking medication regularly, reducing salt intake in the diet, exercising regularly, and monitoring symptoms regularly [7]. Family and friends often play an important role in supporting patient involvement in effective self-care [8]. 
Family as the most important source of support in self-care and family support has a positive influence on self-care maintenance and self-confidence in heart failure patients [9]. The form of family roles to provide support for heart failure patients is shown by the family's ability to care for their family members [10]. The presence of family members is very helpful in treating patients, thereby reducing the rate of treatment failure even though family members cannot replace the professional expertise of health workers [11]. There are some efforts to improve family support. One of the efforts that can be done to increase family support is family empowerment [12].

The concept of family empowerment has been used in care with children with disabilities. Family empowerment is the family's ability to work together with elements outside the scope of life to care for family members who are sick [13]. Family empowerment in the lifestyle of heart failure patients shows significant results, namely more positive changes in their lifestyle, especially in terms of nutrition, spiritual growth, stress management, physical activity, interpersonal communication, and responsibility for health [14].

Patients with heart failure have to take care of themselves, especially when it comes to self-care management. Family empowerment is also important to increase the family's ability to do self-care while at home. The purpose of this study was to determine the correlation between family empowerment and the ability of families to do self-care for heart failure patients in the intermediate care room in Malang.

\section{METHOD}

This study was conducted in a cross-sectional approach with a consecutive sampling technique. The sample in the study was 100 people. The population in this study were families who were waiting in the intermediate care room in Malang. Respondents who took part in this study were included in the inclusion criteria set by the researcher, namely: age of respondents $\geq 18$ years, able to communicate and cooperative in the study, families with blood relations/life partners and live in one house/who live close to the patient's house and are directly involved in care. Data collection used a family empowerment scale (FES) questionnaire containing 34 questions [15] and contribution caregiver self-care heart failure index (CCSHFI), a total of 22 questions [16]. The Pearson correlation test was utilized as the statistical analysis.

\section{RESULTS AND DISCUSSION}

\subsection{Demographic characteristics}

Table 1 describes the demographic characteristics of this study. The Ministry of Health Republic of Indonesia classification system is used to separate the age groups [17]. Based on Table 1, most of the respondents aged 36-45 years old (27\%), where the ages are adults. In adulthood, individuals are able to make wise decisions, begin to ignore personal desires and prioritize family [18]. Besides that, the family relationships that mostly cared for the patients in this study were the wife $46 \%$ and children $26 \%$. Families who care for not only spouses but also children, where the family is an important part of the patient's selfcare [19]. The family plays a role as the main pillar, the most important in society, is responsible for providing adequate care and has an important role in the prevention and treatment of disease [20].

The gender of the most respondents in this study were women $(72.0 \%)$, with a married status of 94 people $(94.0 \%)$ and 54 people $(54.0 \%)$ working. This is in accordance with the culture that exists in Indonesian society which places the role of women in the family as those who take care of their family members [21]. Heart failure itself has a negative impact on a waiting family, especially for a woman because her roles are dual, namely as a mother and also as the head of the family replacing her husband's role which has an impact on physical and emotional changes.

The highest level of education is senior high school $(38 \%)$. The level of family education is also involved as a predictor of the burden of providing care [22]. Families with greater levels of education feel of caring for sick family members as a good experience, but families with lower levels of education see it as a burden because to a lack of information and awareness of the issues they confront [23].

\subsection{Family empowerment}

Table 2 shows the mean value of the components of family empowerment. Based on Table 2, it shows that the knowledge component has the highest mean valueand the efficiency of the component has the lowest mean value. Family empowerment is a combination of attributes, attitudes, and behaviors that enable families and health-care providers to meet the needs of sick family members in ways that benefit everyone involved, such as increasing family involvement in care, improving family and patient psychology, and increasing service satisfaction [24]. The wrong family assumption can have a fatal impact on the patient, worsening the patient's quality of life. To anticipate this, the right and good way is to provide education to families [25]. Education is a component of the family empowerment intervention model, which aims to improve family knowledge so that they can better care for patients [26]. 
Empowerment is a learning concept, and through learning, a person is expected to be independent in doing something to achieve goals. For that we need confidence from the family to be able to help recovery for patients with heart disease. The existence of family self-efficacy support, and mild to strong selfconfidence in the family will help identify the needs and care needed by families and patients [27].

\begin{tabular}{lcc}
\multicolumn{3}{c}{ Table 1. Demographic distribution } \\
\hline \multicolumn{1}{c}{ Characteristics } & $\mathrm{n}$ & $\%$ \\
\hline Age & & \\
17-25 years old (late adolescence) & 5 & 4.0 \\
26-35 years old (early adulthood) & 14 & 14.0 \\
36-45 years old (late adulthood) & 27 & 27.0 \\
46-55 years old (early old age) & 26 & 26.0 \\
56-65 years old (late old age) & 22 & 22.0 \\
>65 years old (old age) & 6 & 6.0 \\
Gender & & \\
Male & 28 & 28.0 \\
Female & 72 & 72.0 \\
Educational level & & \\
Not going to school & 11 & 11.0 \\
Elementary school & 12 & 12.0 \\
Junior high school & 14 & 14.0 \\
Senior high school & 38 & 38.0 \\
Collage & 25 & 25.0 \\
Job status & & \\
Not a work & 46 & 46.0 \\
Work & 54 & 54.0 \\
Marital status & & \\
Single & 6 & 6.0 \\
Married & 94 & 94.0 \\
Relationship with patients & & \\
Husband & 17 & 17.0 \\
Wife & 46 & 46.0 \\
Child & 26 & 26.0 \\
Grandchild & 1 & 1.0 \\
Other & & 10.0 \\
\hline & & \\
& &
\end{tabular}

Table 2. Family empowerment component

\begin{tabular}{ccc}
\hline Component of family empowerment & Mean & SD \pm \\
\hline Advocacy & 31.76 & 4.073 \\
Knowledge & 41.48 & 4.873 \\
Competency & 30.64 & 3.675 \\
Efficacy & 23.15 & 2.086 \\
\hline
\end{tabular}

\subsection{The ability of a patient's family to provide self-care in heart failure}

Table 3 shows the mean value of the component self-care. Based on the data from Table 3, it shows that the component with the highest mean value is the self care maintenance and the component with the lowest value is the self-care management indicator. Factors that influence the mean value in the domain of self-care maintenance are families who think that there is no need to remind their families to measuring weight, do physical activity, reduce salt, take medication, control doctors because of their wrong understanding, because patients do not feel there are complaints and have high blood pressure. Whereas in self-care management, families also think that there is no need to reduce drinking water because drinking lots of water is good for health, and the answers of respondents on average never take additional drugs, namely furosemide when the patient experiences tightness, swelling in the legs because they do not consult. With a doctor first, the average family immediately brought the patient to the hospital and never called/consulted a nurse/doctor to ask for directions. Factors that influence self-care include experience and skills, motivation, habits, beliefs and cultural values and support from family [6].

Table 3. Self-care component

\begin{tabular}{ccc}
\hline Component of self-care & Mean & $\mathrm{SD} \pm$ \\
\hline Self-care maintenance & 20.34 & 5.230 \\
Self-care management & 11.69 & 2.813 \\
Self-care confidence & 16.25 & 3.020 \\
\hline
\end{tabular}

Int J Public Health Sci, Vol. 11, No. 1, March 2022: 248-253 
Family plays an important role in supporting the success and effectiveness of self-care in heart failure patients [8]. In patients with heart failure, it is difficult to do self-care independently because the disease requires family support. Support from a partner is what the patient needs, which is seen from the interview results of a man with heart failure aged 58 years old who said his wife always helped him in preparing medicine beforehand so that his motivation for self-care increased [28]. Family is an inseparable part according to the family center concept that the family is an active collaborator, cognitive support including participatory information sharing and family education will improve family coping during the disease experience [29]. Nurses have a role to continue to improve family self-care in the domains of selfcare maintenance, self-care management and self-care confidence. Self-care behavior is important for maintaining clinical stability and preventing the incidence of recurrent hospitalizations [30].

\subsection{Correlation family empowerment with ability families does self care}

Table 4 shows the correlation family empowerment with ability families do self care. Based on Table 4 , the p-value is $0.000<0.05$, which means that there is a significant correlation between family empowerment and the ability of families to do self-care with a correlation value of $0.522 * *$. Based on the principle of the family's ability to do self-care, all aspects of empowerment will mutually influence and influence self-care.

Table 4. Correlation family empowerment with ability families to do self-care

\begin{tabular}{cccc}
\hline & & Family empowerment & The ability families to do self-care \\
\hline Family empowerment & Pearson correlation & 1 & $.522^{* *}$ \\
& Sig (2-tailed) & & .000 \\
The ability families do self-care & $\mathrm{N}$ & 100 & 100 \\
& Pearson correlation & $.522^{* *}$ & 1 \\
& Sig (2-tailed) & .000 & 100 \\
\hline
\end{tabular}

Professional nurses must be able to assess patients not only based on the illness but also see the presence of the family that can affect the patient's condition [31]. Nursing interventions are offered not only to patients, but also to their families, in order for families to improve their abilities to care for patients [32]. Family empowerment as referred to in this study is a form of family participation to assist patient self-care in the form of physical competence and knowledge. Empowerment is a process, through this process families can analyze the real causes of the problem, they are ready to solve problems wisely, share knowledge and skills with health workers [33]. Family empowerment helps families through the process of change that will be carried out, building family resilience and adaptation, exploring and increasing the potential, roles and functions that the family has [34]. Empowerment of families with family members who experience chronic diseases is done by providing complete and accurate information about disease conditions and treatment management, promoting empathy and showing genuine concern, this can increase family competence in caring for sick family members [35].

The significance of family education regarding heart failure therapy may be accomplished through family empowerment while in the hospital, which will enhance family and patient knowledge in self-care, and families will be able to regulate the signs and symptoms that patients will encounter. In the self-care practice of heart failure patients, there is a need for "multiple players" (such as family members) on the patient's success in self-care behaviors that require basic knowledge to improve adherence (how to prepare low-sodium foods) [36]. There is evidence that self-care management programs in heart failure patients can be more successful when knowledge of heart failure management and family involvement increases [19]. Having effective self-care for heart failure patients has the potential to increase clinical endpoints such as a lower risk of repeated hospitalizations [30]. Therefore, with the empowerment, it is hoped that families will be able to carry out independent care while at home, improve health outcomes, increase satisfaction, and get adherence in treatment of heart failure patients.

\section{CONCLUSION}

In heart failure patients, there is a high correlation between family support and their ability to selfcare. The lack of family empowerment and self-care is caused by multiple factors. Lack of knowledge about heart failure treatments can be fatal for heart failure patients. The importance of education in families to help patient self-care so as to improve quality of life, prevent rehospitalization. The role of nurses in providing education to patients and families to carry out independent care at home. 


\section{REFERENCES}

[1] P. Ponikowski et al., "Heart failure: preventing disease and death worldwide," ESC Heart Failure, vol. 1, no. 1, pp. 4-25, 2014, doi: 10.1002/ehf2.12005.

[2] M. Gheorghiade, M. Vaduganathan, G. C. Fonarow, and R. O. Bonow, "Rehospitalization for heart failure: Problems and perspectives," Journal of the American College of Cardiology, vol. 61, no. 4, pp. 391-403, Jan. 2013, doi: 10.1016/j.jacc.2012.09.038.

[3] M. R. Cowie et al., "Improving care for patients with acute heart failure: before, during and after hospitalization," ESC Heart Failure, vol. 1, no. 2, pp. 110-145, Dec. 2014, doi: 10.1002/ehf2.12021.

[4] A. S. Desai and L. W. Stevenson, "Rehospitalization for heart failure: predict or prevent?," Circulation, vol. 126, no. 4, pp. 501506, Jul. 2012, doi: 10.1161/CIRCULATIONAHA.112.125435

[5] J. Xu et al., "Heart failure rehospitalization and delayed decision making: the impact of self-care and depression," $J$ Cardiovasc Nurs, vol. 33, no. 1, pp. 30-39, 2018, doi: 10.1097/JCN.0000000000000423.Heart.

[6] T. Jaarsma, J. Cameron, B. Riegel, and A. Stromberg, "Factors related to self-care in heart failure patients according to the middle-range theory of self-care of chronic illness : a literature update," Curr Heart Fail Rep, vol. 14, pp. 71-77, 2017, doi: 10.1007/s11897-017-0324-1.

[7] B. Riegel, C. S. Lee, V. V. Dickson, and B. Carlson, "An update on the self-care of heart failure index," Journal of Cardiovascular Nursing, vol. 24, no. 6, pp. 485-497, 2009, doi: 10.1097/JCN.0b013e3181b4baa0.

[8] B. Riegel, T. Jaarsma, and A. Stromberg, "A middle-range theory of self-care of chronic illness," Advances in Nursing Science, vol. 3, no. 35, pp. 194-204, 2012, doi: 10.1891/9780826159922.0016.

[9] Y. Chen, H. Zou, Y. Zhang, W. Fang, and X. Fan, "Family caregiver contribution to self-care of heart failure: an application of the information-motivation-behavioral skills model," Journal of Cardiovascular Nursing, vol. 32, no. 6, pp. 576-583, 2017, doi: 10.1097/JCN.0000000000000398.

[10] A.-M. Rosland, M. Heisler, H. Choi, M. J. Silveira, and J. D. Piette, "Family influences on self-management among functionally independent adults with diabetes or heart failure," Chronic Illn, vol. 6, no. 1, pp. 22-33, 2013, doi: 10.1177/1742395309354608.Family.

[11] L. S. Franck and K. O. Brien, "The evolution of family-centered care: from supporting parent-delivered interventions to a model of family integrated care," Birth Defects Research, no. May, pp. 1-16, 2019, doi: 10.1002/bdr2.1521.

[12] S. S. Olin et al., "The application of behavior change theory to family-based services: improving parent empowerment in children's mental health," J Child Fam Stud., vol. 19, no. 4, pp. 462-470, 2010, doi: 10.1007/s10826-009-9317-3.The.

[13] R. Wakimizu, H. Fujioka, K. Nishigaki, and A. Matsuzawa, "Family empowerment and associated factors in Japanese families raising a child with severe motor and intellectual disabilities," International Journal of Nursing Sciences, vol. 5, no. 4, pp. 370376, 2018, doi: 10.1016/j.ijnss.2018.09.006.

[14] M. Rakhshan, K. R. Kordshooli, and S. Ghadakpoor, "Effects of family-center empowerment eodel on the lifestyle of heart failure patients: a randomized controlled clinical trial," International Journal of Community Based Nursing and Midwifery, vol. 3, no. 4, pp. 255-262, 2015.

[15] N. N. Singh, W. J. Curtis, C. R. Ellis, M. W. Nicholson, T. M. Villani, and H. A. Wechsler, "Psychometric aalysis of the family empowerment scale," Journal of Emotional and Behavioral Disorders, vol. 3, no. 2, pp. 85-91, Apr. 1995, doi: $10.1177 / 106342669500300203$.

[16] E. Vellone, "Caregiver contributions to self-care in heart failure: developing an instrument and identifying the determinants and impact of caregiver contributions on patients and caregivers ercole," 2014.

[17] Ministry of Health of the Republic of Indonesia, Indonesian health data profile 2009 (In Indonesia: profil data Kesehatan Indonesia Tahun 2009). Jakarta: Kementrian Kesehatan Republik Indonesia, 2010

[18] W. B. De Bruin, A. M. Parker, and B. Fishhoff, "Explaining adult age differences in decision-making competence," Journal of Behavioral Decision Making, vol. 25, pp. 352-260, 2012, doi: 10.1002/bdm.712.

[19] J. T. Bidwell et al., "Shared heart failure knowledge and self-care outcomes in patient-caregiver dyads," Heart and Lung, vol. 47, no. 1, pp. 32-39, 2018, doi: 10.1016/j.hrtlng.2017.11.001.Shared.

[20] M. Park and C. K. Chesla, "Understanding complexity of asian american family care practices," Archives of Psychiatric Nursing, vol. 24, no. 3, pp. 189-201, 2010, doi: 10.1016/j.apnu.2009.06.005.

[21] Y. Afiyanti and S. M. Solberg, "It is my destiny as a woman': On Becoming a New Mother in Indonesia YatiTranscultural Nursing," Journal of Transcultural Nursing, pp. 1-8, 2014, doi: 10.1177/1043659614526243.

[22] M. M. Bayoumi, "Subjective burden on family carers of hemodialysis patients," Open Journal of Nephrology, vol. 04, no. 02, pp. 79-85, 2014, doi: 10.4236/ojneph.2014.42011.

[23] V. O. Lasebikan and O. O. Ayinde, "Family burden in caregivers of schizophrenia patients : prevalence and Socio-demographic correlates," Indian Journal of Psychological Medicine, vol. 35, no. 1, 2013, doi: 10.4103/0253-7176.112205.

[24] K. Casagrande and B. R. Ingersoll, "Improving service access in ASD: a systematic review of family empowerment interventions for children with special healthcare needs," Review Journal of Autism and Developmental Disorders, vol. 8, no. 2, pp. 170-185, Jun. 2021, doi: 10.1007/s40489-020-00208-9.

[25] M. S. Khan et al., "High prevalence of lack of knowledge of symptoms of acute myocardial infarction inPakistan and its contribution to delayed presentationto the hospital," BMC Public Health, vol. 7, no. 1, p. 284, Dec. 2007, doi: 10.1186/14712458-7-284.

[26] N. Nurhaeni, Y. Rustina, N. Agustini, and N. Enis Rosuliana, "Impact of family empowerment model on satisfaction and children's length of stay in hospital," Enfermería Clínica, vol. 28, pp. 36-40, Feb. 2018, doi: 10.1016/S1130-8621(18)30033-0.

[27] T. Steigleder, R. Kollmar, and C. Ostgathe, "Palliative care for stroke patients and their families: barriers for implementation," Frontiers in Neurology, vol. 10, no. March, pp. 1-8, Mar. 2019, doi: 10.3389/fneur.2019.00164

[28] P. M. Shahrbabaki, E. Nouhi, M. Kazemi, and F. Ahmadi, "Defective support network: a major obstacle to coping for patients with heart failure: a qualitative study," Global Heatlh Action, vol. 9, pp. 1-8, 2016, doi: 10.3402/gha.v9.30767.

[29] B. A. Girgin and B. B. Sivri, "The importance of family centered care and assessment," Global Journal of Health Science, no. 7, pp. 29-33, 2015, doi: 10.13140/RG.2.1.4185.3925.

[30] S. Toukhsati, T. Jaarsma, A. Babu, A. Driscoll, and D. Hare, "Self-care interventions that reduce hospital readmissions in patients with heart failure; towards the identification of change agents," Clinical Medicine Insights: Cardiology, vol. 13, p. 117954681985685, Jan. 2019, doi: 10.1177/1179546819856855.

[31] Y. Choi, S. J. Bosch, and L. Ap, "Environmental affordances : designing for family presence and involvement in patient care," Health Environtment Research \& Design Journal, vol. 6, no. 4, pp. 53-75, 2013. 
[32] M. D. Parra, C. C. Torres, L. B. Arboleda, R. R. Carvajal, S. Franco, and J. Santos, "Effectiveness of an educational nursing intervention on caring ability and burden in family caregivers of patients with chronic non-communicable diseases. A preventive randomized controlled clinical trial," Investigacion y Educacion en Enfermeria, vol. 37, no. 1, 2019, doi: 10.17533/udea.iee.v37n1e04.

[33] M. Shoghi, B. Shahbazi, and N. Seyedfatemi, "The effect of the family-centered empowerment model (FCEM) on the care burden of the parents of children diagnosed with cancer," Asian Pacific Journal of Cancer Prevention, vol. 20, pp. 1757-1764, 2019, doi: 10.31557/APJCP.2019.20.6.1757.

[34] D. M. Whitley, S. J. Kelley, D. M. Whitley, S. J. Kelley, and P. E. Campos, "Perceptions of family empowerment in african american custodial grandmothers raising grandchildren: thoughts for research and practice," The Journal of Contemporary social services, vol. 92, pp. 383-389, 2011, doi: 10.1606/1044-3894.4148.

[35] I. Luthfa and I. Ardian, "Effects of family empowerment on increasing family support in patients with type-2 diabetes mellitus," Nurse Media Journal of Nursing, vol. 9, no. 1, pp. 58-68, 2019, doi: 10.14710/nmjn.v9i1.22501.

[36] B. Riegel, V. V. Dickson, and K. M. Faulkner, "The situation-specific theory of heart failure self-care revised and updated," Journal of Cardiovascular Nursing, vol. 31, no. 3, pp. 226-235, 2016, doi: 10.1097/JCN.0000000000000244.

\section{BIOGRAPHIES OF AUTHORS}

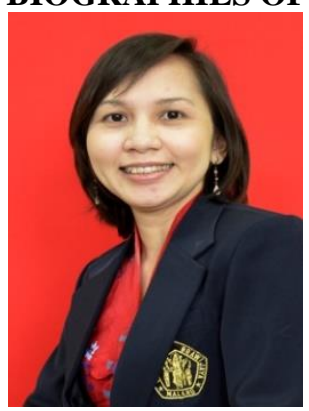

Alfrina Hany (i) SI SC P is a lecturer at the Universitas Brawijaya Indonesia's Faculty of Medicine's Department of Medical Surgical Nursing. She is involved in humanitarian efforts as well as research in nursing domains such as acute care, critical care, disaster and chronic nursing. She can be contacted at email: hanie.fk@ub.ac.id.

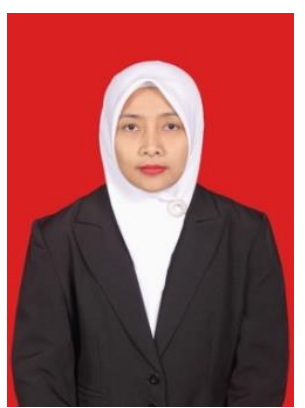

Eni Yulistianingsih (iD) 8 SC P works as a nurse in Saiful Anwar General Hospital Malang hospital. She works in Medical Surgical and Critical care Ward. She had formerly enrolled in Brawijaya University's Nursing undergraduate program. She may be reached by email at: yulistiajine@gmail.com.

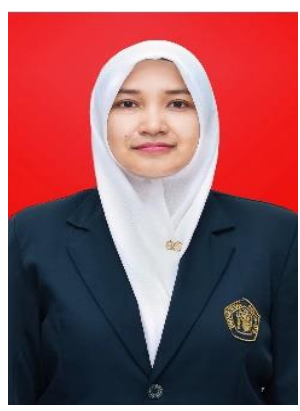

Bintari Ratih Kusumaningrum (iD $8 \mathrm{SC} P$ is a lecturer at the University of Brawijaya Indonesia in the emergency nursing department. She actively participates in emergency training in nursing. Her research experience is mostly in the field of emergency nursing. She can be contacted at email: bintarirk@gmail.com. 